\title{
Initial Exploration of Types and Significance of Kitchen God Paper-Charm
}

\author{
Yongfeng Huang \\ Department of Philosophy \\ Xiamen University \\ Xiamen, China
}

\author{
Luansheng Lin \\ Department of Chinese Language and Literature \\ Ningde Normal University \\ Ningde, China
}

\begin{abstract}
Worshipped by almost all Chinese people, Kitchen God mainly plays a role of "Say good things to God, guard people in the world." Chinese people often paste up Kitchen God paper-charm in their kitchens and hold ceremonies to worship kitchen god. There are single layer, bilayer and three-layer patterns and other special types of Kitchen God paper-charm. Its variety and development reflects people's dream of living in happiness through religious belief.
\end{abstract}

Keywords-China; worship of Kitchen God; Paper-Charm

\section{INTRODUCTION}

There are many different ways to say Kitchen God, such as Kitchen Bodhisattva and Kitchen King. It is worshipped by Chinese people from royal to ordinary people. Paper-charm is a kind of paper used to offer sacrifice, on which pattern of god or Buddha is drawn. Kitchen God paper-charm, also known as KGPC, is a kind of paper charm with Kitchen God and other related gods' patterns on. According to Volume 148-Custom, Anecdotes in Old Beijing by Yu Minzhong in Qing Dynasty quoted from Generalized Yueling (Yueling means climate and phenology in a lunar month): "Carve the pattern of Kitchen God and type it on paper, then there is paper-charm of kitchen god; almost all people go and buy it to burn it on December 24th in Chinese lunar calendar, which means to send Kitchen God to God. Prepare candy cake for Kitchen God and black beans and grasses for his horse, then all family members gather in line behind the altar saying 'Whether they taste good or not, please don't be angry.' This ceremony will last to January 1st in lunar calendar next year" [1] Anecdotes in Old Beijing named by Emperor Qianlong has explained all the procedure when worshipping Kitchen God.

Before Han Dynasty, main duty of Kitchen God is to deal with things related to people's diet. While since Wei and Jin Dynasty, he does not only deal with diet, but also judge right or wrong things done by people. The change of his function can be described as "Say good things to God, guard people in the world." Kitchen God is close to people's lives with power, so people respect him but they are also afraid of him. People welcome Kitchen God before the lunar New Year and see him off after it by pasting Kitchen God Paper-Charms, in the hope of living in happiness and safety.

Based on initial exploration of types and significance of Kitchen God paper-charm, we can know people's way of worshipping Kitchen God and secret of Chinese culture. Its diversity is resulted from time period, regional difference and people's lives' experience. According to the materials collected by the author and those from Chinese Kitchen Culture Museum in Zhengzhou, Henan province, varieties of Kitchen God paper-charms are as follow:

\section{Single LAYer PAPER-Charm}

There are different kinds of single layer paper-charm.

\section{A. With Kitchen God Himself}

As we can see in Paper-Charm 1, there is only Kitchen God with a dog on both sides beside the table as guards without his wife, which is simple but with a long-term meaning "Fig. 1".

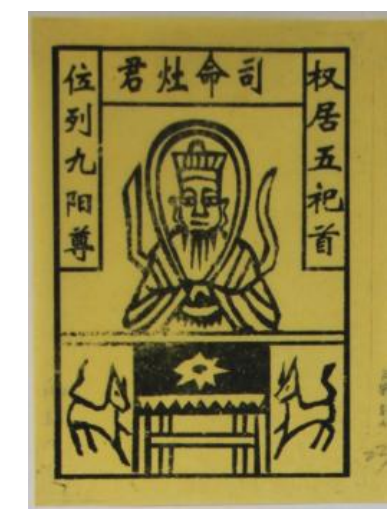

Fig. 1. Paper-Charm 1

\section{B. Kitchen God with One Wife God}

From Paper-Charm 2, we can see that there is one small people in each side of Kitchen God and his wife. These two people belong to gods of kitchen range, but their roles aren't clear, probably be assistants such as water transiting boy or firewood transiting girl. There are burner, candlestick and silk bag behind the table which inflect auspiciousness and wealth. It is colorful with happiness. And from this paper-charm, we can know people are delightful and trying to pray for next year before the Spring Festival "Fig. 2". 


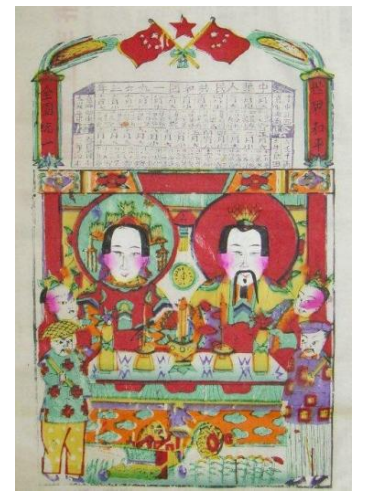

Fig. 2. Paper-Charm 2

\section{Kitchen God with Two Wife Gods}

Paper-Charm 3 and 4 take Kitchen God as the main god, because his pattern occupies much of the whole paper-charm. The focus is Kitchen God, while two wife gods are like maid servants who serve as foils because of the emotional need and entertainment feeling of people. Perhaps people want to make Kitchen God say good to the God through his wife, which also reflects the combination of Yin and Yang. Meanwhile, as a kind of art, paper-charms pay attention to symmetry and a little change on it "Fig. 3" "Fig. 4".

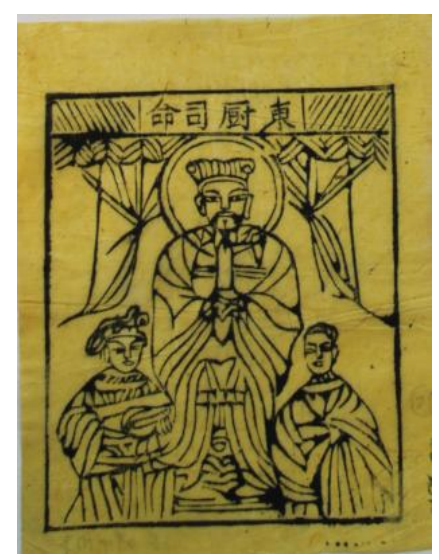

Fig. 3. Paper-Charm 3

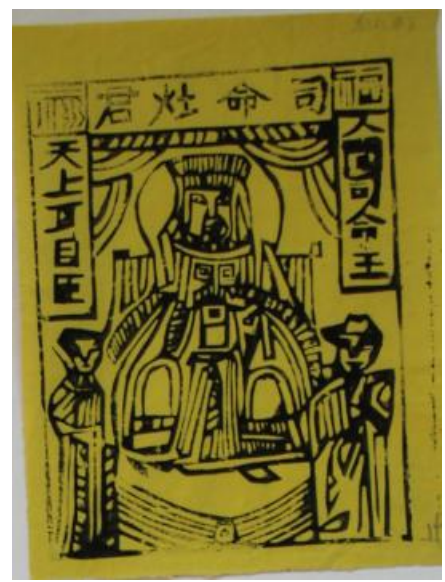

Fig. 4. Paper-Charm 4

\section{BILAYER PAPER-CHARM}

It includes the following 2 types:

\section{A. With One Wife God}

See in Paper-Charm 5, Kitchen God and his wife are on the first layer with blessed water boy and fire friendly boy around them. The second layer shows a scene of Kitchen God riding on a horse to the Heavenly Southern Gate for reporting things happened in the world. In spatial arrangement, Kitchen God couple is in the first layer, while the Heaven is in the second layer, which is different from that in Paper-Charm 6. In this paper-charm, we can see that Kitchen God couple is in the second layer. And in the first layer, we can see that all the family members are welcoming the God of Wealth. From these two patterns, we can get that Kitchen God serves as a junction between God and ordinary people. This kind of paper-charm is colorful with happy feeling "Fig. 5" "Fig. 6".

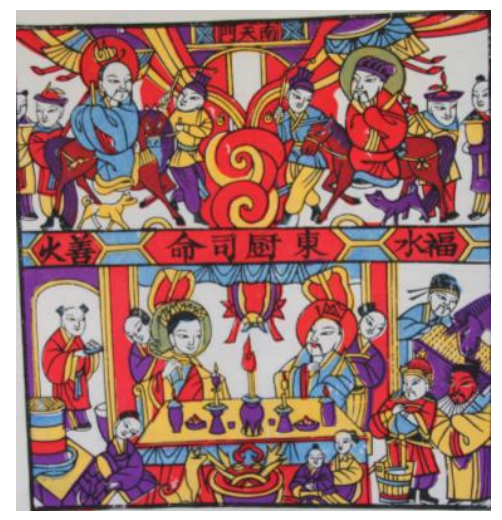

Fig. 5. Paper-Charm 5

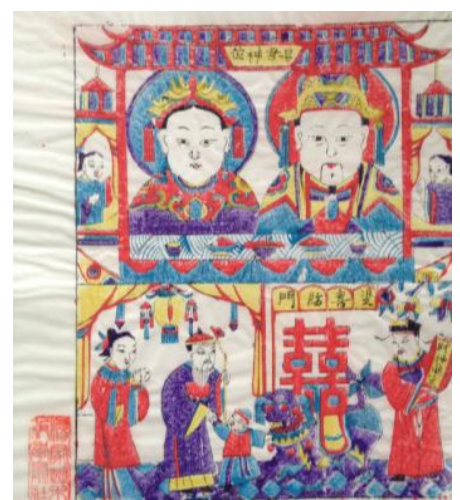

Fig. 6. Paper-Charm 6

\section{B. With Two Wife Gods}

The main difference of these two paper-charms lies in color, content and the position of Kitchen God couple. PaperCharm 7 is a colorful one with red which is the primary color of Kitchen God paper-charm as its main color implicating wealth, happiness and goodness. What's more, Kitchen God couple is on the second layer. Paper-Charm 8 is a black and white one, Kitchen God couple is on the first layer. On the 
head of Paper-Charm 7 is a calendar, while there is a money tree with gods of kitchen field in Paper-Charm 8. Both have reflected people's worship of Kitchen God and pursuing of happiness. But sometimes black and white color may be attractive "Fig. 7" "Fig. 8".

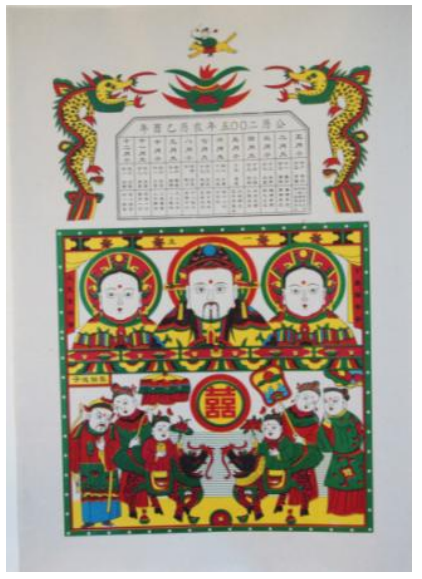

Fig. 7. Paper-Charm 7

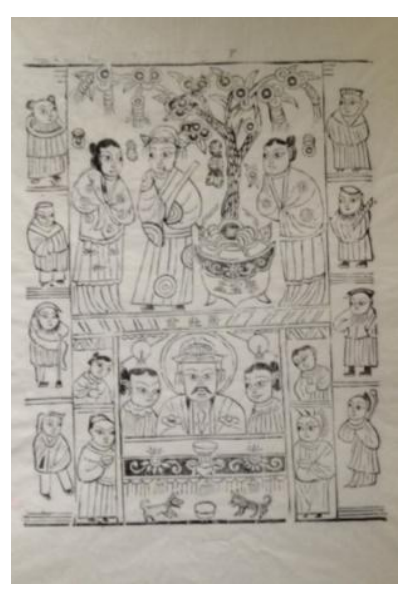

Fig. 8. Paper-Charm 8

\section{THREE LAYER PAPER-CHARM}

It can be divided into the following types:

\section{A. With One Wife God}

The main character of Paper-Charm 9 is Kitchen God couple who is on the second layer. God of Wealth is on the first layer, and treasure bowl represents more money and wealth which is in central is also an important factor of papercharm. Sending child Bodhisattva is on the third layer with Eight Immortals on both sides, which implicates that people can overcome difficulties by their efforts. In Paper-Charm 10, Kitchen God couple is also on the second layer with a treasure bowl between them. But they the couple is not the main character in this picture, on the contrary, Kitchen Gods on the first and third layer are the focuses of this picture. All the related gods are around them, which highlights the position of Kitchen God. And same to Paper-Charm 9, Eight Immortals are also on their sides. This kind of paper-charm which can be usually seen seems crowded with many characters on the picture "Fig. 9" "Fig. 10".

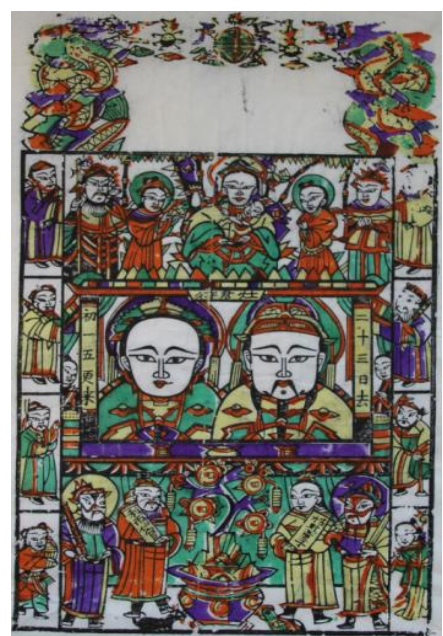

Fig. 9. Paper-Charm 9

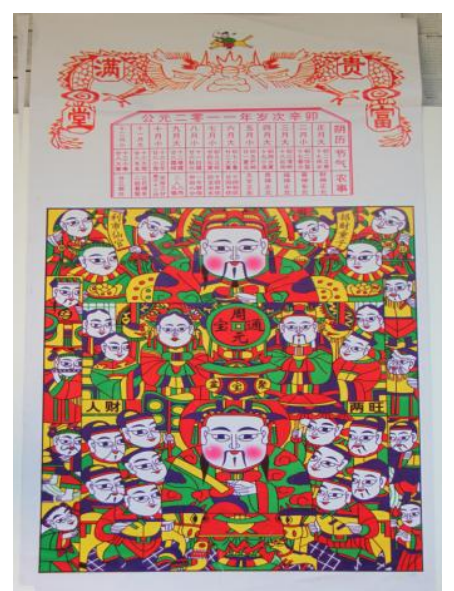

Fig. 10. Paper-Charm 10

\section{B. With Two Wife Gods}

Paper-Charm 11 mainly presents a scene of Kitchen God and his two wives. Other characters are Eight Immortals and other related gods. Though it is colorful, it can help stress out Kitchen God couple with fine art technique. In big size and on the highest position, Kitchen God couple is the main character in this picture "Fig. 11". 


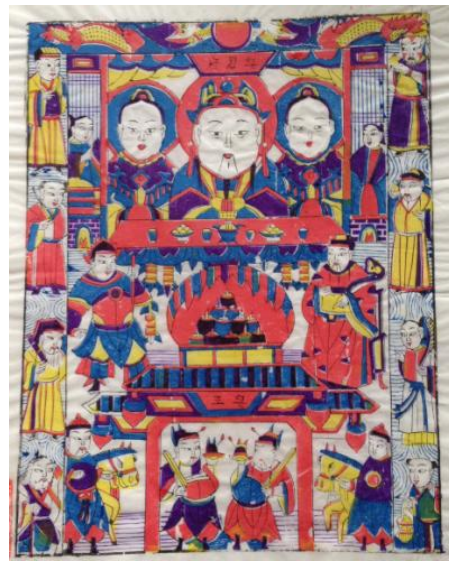

Fig. 11. Paper-Charm 11

\section{SPECIAL TYPES}

What we have introduced above can mainly be divided into layer type and Kitchen God couple type. While the following are special ones which can help the explanation of people's action on worshipping Kitchen God.

\section{A. Special Image}

As we can see in Paper-Charm 12, the image of Kitchen God is related to God of Fire, which is different from elder people and officers later. In the central of his forehead, there is an eye for the supervision of people's activities in the world. He same time, there is sward in his hand, which represents his power on offering award and punishment. It is a different kind of art presents in a dimensional way by difference in color, which is attractive and vivid "Fig. 12".

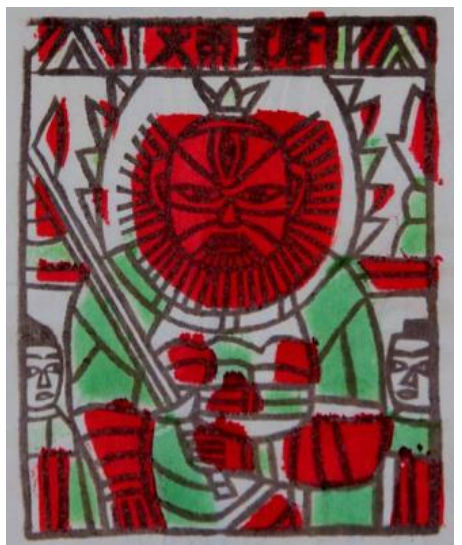

Fig. 12. Paper-Charm 12

\section{B. Special Scene}

In both of these two Paper-Charms 13 and 14, Kitchen God occurs in the Kitchen. When cooks are preparing meals, he rises up in smoke. This scene is obviously different from others. Instead of sitting there in a strict manner, he appears to be active. In this way, it can help reflect the close relation between people and Kitchen God, which is imaginative and attractive "Fig. 13" "Fig. 14".

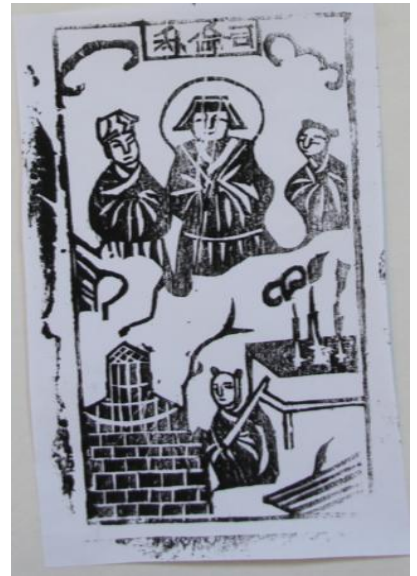

Fig. 13. Paper-Charm 13

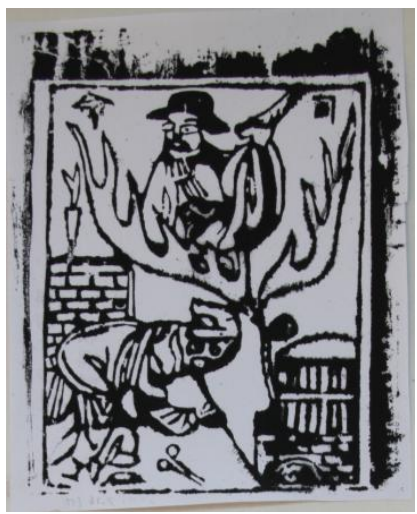

Fig. 14. Paper-Charm 14

\section{Special Time}

The following two Paper-Charms 15 and 16 were in the time around the Cultural Revolution. With the slogan of "overthrow all ghosts and monsters", Kitchen God had been the target unavoidably. Therefore, all the characters were changed at that time. Kitchen God couple became ordinary people with smile; all the related gods became younger generation of a family; while the Eight Immortals also turned into eight ordinary people. All the gods became ordinary people. But the main color was still red and yellow which can help the explanation of luck and happiness. This kind of PaperCharm is filled with the spirit of time and reflects the development of folk religion "Fig. 15" "Fig. 16". 


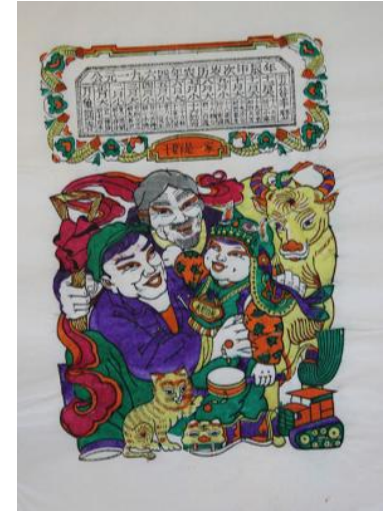

Fig. 15. Paper-Charm 15



Fig. 16. Paper-Charm 16

There are features of Kitchen God paper-charm: firstly, its universality in belief dimension. All families have their own kitchen range, even now we use gas cooker which is different from that in ancient times. But their function and cultural meaning are the same. Kitchen range is a main factor of a family, and family is a unit when carrying out activities. In Confucianism, self- cultivation is its basic method. It can be explained as regulating the family, ruling the state and pursuing world peace in the country level. Regulating the family is the priority, without this practice, one can't rule the state, let alone pursue world peace. In this case, we can know the importance of family in Chinese culture. And kitchen range is the main factor of a family. We call family division as to set up a separate kitchen; the family broken up and decimated as broken-up of kitchen range. It can be easily seen that kitchen range is one of the most important factors of a family. Because it represents diet and generation, food and sex can be reflected by kitchen culture. So Kitchen god is widely worshipped by Chinese people. The complex feeling by people to Kitchen god can be seen as their worship attitude in the end. And in this way, it is popular in rural area in Sichuan, Fujian, Guangzhou, Hainan, Hubei, Hunan, Jiangxi and other provinces where people are still offering sacrifice to Kitchen God in lunar year (in which the last month has 29 days).

Secondly, it has unity in artistic creation. First, for unity in color, besides black and white picture, other paper-charms are mainly red and yellow, because these two colors means bright and warm and represents wealth, peace and all good things. In this way, red and yellow are widely used in Kitchen God paper-charm with folk spirit. Second, unite in image. Though there is difference among Kitchen God characters we have mentioned above, they are all like kind elders, officers and ordinary people, lacking sacred feeling, while it reflects close relation between Kitchen God and ordinary people. In fact, Chinese people are living in religious belief all the time like worshiping Kitchen god. While because it is just like part of their daily life, they do not take it as religious belief. This kind of religious belief has played an important role the stability and harmony of society.

The occurrence of each kind of Kitchen God paper-charm has one common reason which is the demand from the society. If there is no demand of a certain kind, it will decline or disappear gradually, especially for those in modern time. In the areas of Jiangsu and Zhejiang which are mainly influenced by Chu Culture, most people are worshipping Kitchen God. While the development of Kitchen God paper-charm has declined recently, let alone that in central plain and northeast China. After visiting many families in Qidu Town in Ningde City of Fujian Province, the author has found that fewer families are using paper-charm, and some of them are using plastic ones. Development is effected by demand. If there is large demand it can be well developed, while if there is less demand, it will become decline. Whether rise or decline, it still has distinctive features in cultural level.

\section{REFERENCES}

[1] Complete Library in the Four Branches of Literature with Pictures, Pavilion of the Imperial Library Volume 499, Taiwan Commercial Press, 1986, Page 292. 